\title{
Molecular tectonics: generation of 1- and 2-D copper coordination networks by positional isomeric tectons based on phenylenediamine backbone bearing two isonicotinoyl moieties
}

\author{
¿ Jérôme Pansanel, Abdelaziz Jouaiti, Sylvie Ferlay, Mir Wais Hosseini* Jean-Marc Planeix and Nathalie \\ Kyritsakas
}

\author{
Receipt/Acceptance Data [DO NOT ALTER/DELETE THIS TEXT] \\ Publication data [DO NOT ALTER/DELETE THIS TEXT] \\ ${ }_{10}$ DOI: 10.1039/b000000x [DO NOT ALTER/DELETE THIS TEXT]
}

\begin{abstract}
The combination of three isomeric organic tectons 1-3 based on 1,2-, 1,3- and 1,4phenylenediamine backbones bearing two isonicotinoyl with $\mathrm{Cu}(\mathrm{OAc})_{2}$ neutral complex leads to the formation of 1-D and 2-D coordination networks. Whereas for both tectons $\mathbf{1}$ and $\mathbf{2}$ the network is generated through the interconnection of the organic moieties by copper dimers of the paddle15 wheel type, in the case of $\mathbf{3}$, the 2-D network is formed by another type of connector, a binuclear copper complex for which the two metal centres adopt an octahedral coordination geometry.
\end{abstract}

\section{Introduction}

The design of molecular architectures in the solid state is a subject of current interest. In particular, the formation of 20 coordination networks, ${ }^{1}$ hybrid metallo-organic molecular assemblies, is attracting much attention over the last decade. ${ }^{2}$ The formation of this type of network results from the establishment of coordination bonds between a metal or a metal complex and a donor atom belonging to an organic 25 building block called tecton., ${ }^{3,4}$ Self-assembly processes are responsible for the formation of such infinite architectures. This construction strategy based on iterative processes may lead to structural complexity even when rather simple tectons are engaged. ${ }^{5}$ For that reason, although many types of 30 coordination networks have been reported over the last years, the precise design of these networks in terms of connectivity (type and number of coordination bonds) and dimensionality (depending on the number of translations of the coordination event leading to chains (1-D), sheets (2-D) and three35 dimensional arrangements (3-D)) still remains a challenge. In terms of design, in order to reach an acceptable degree of confidence, systematic investigations are needed. In particular, the study of the incidence of (i) the nature of binding sites and poles of the organic building block, their 40 number and disposition in space, (ii) the number and disposition of available coordination sites on the metal centre, (iii) steric and electrostatic constraints, (iv) the nature and binding ability of anions present, (v) the solvent used, (vi)

Laboratoire de Chimie de Coordination Organique, UMR CNRS 7140, Université Louis Pasteur,

F-67000 Strasbourg, France; E-mail: hosseini@chimie.u-strasbg.fr

e-mail : hosseini@,chimie.u-strasbg.fr

$\dagger$ Electronic Supplementary Information (ESI) available: [details of any supplementary information available should be included here]. See http://dx.doi.org/10.1039/b000000x/ kinetics or thermodynamic control of crystallisation, must be 45 undertaken. For some time now we are engaged in a systematic study of these parameters. ${ }^{6}$

We report here our investigation dealing with the possibility of controlling the geometry (bent angle) of stair type 1-D coordination networks using a combination of three isomeric 50 tectons 1-3 (Scheme 1) with copper(II) acetate which generally behaves as a linear connector.
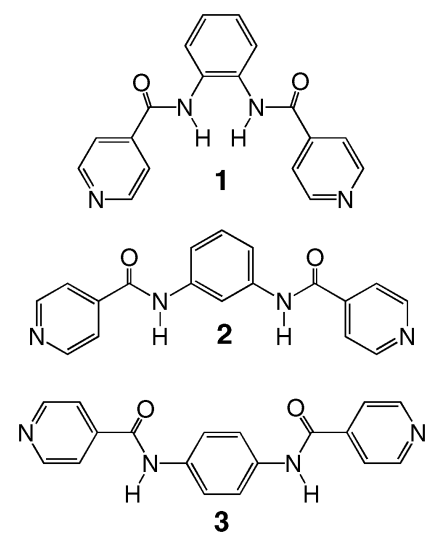

Scheme 1

\section{${ }_{55}$ Results and discussion}

The goal of this investigation is to study both the correlation between structural features of a rather rigid tecton such as the angle between two monodentate coordinating sites with the geometry of the generated coordination networks when 60 combined with the bimetallic copper(II) acetate as connector (Scheme 2) and the connectivity and geometry of the bimetallic unit. 


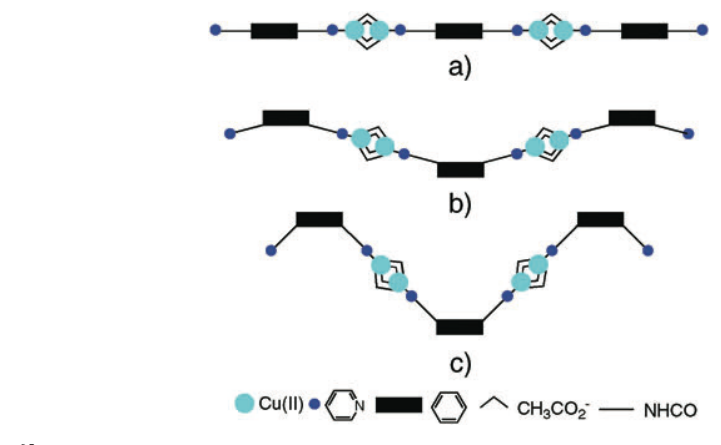

Scheme 2

In order to obtain restricted conformational space, rather rigid ligands are required. For that reason, the design of the organic 70 bismonodentate tectons 1-3 (Scheme 1) is based on the aryl group bearing two coordinating pyridine units oriented in a divergent fashion. The aryl backbone is connected to pyridines through amide junctions. The three tectons are positional isomers. Indeed, they only differ by the position of 75 connection of pyridyl units to the aryl group (ortho for $\mathbf{1}$, meta for $\mathbf{2}$ and para for $\mathbf{3}$ ). Although all three parts (aryl, pyridine and amide group) are rigid units, nevertheless, due to rotational flexibility, tectons 1-3 may adopt different conformations and configurations. ${ }^{7,8,9}$ The formation of 80 coordination networks by combining 1-3 with a variety of metal cations has already been reported : $\mathrm{Hg}, \mathrm{Ag}$ and $\mathrm{Au}$ for $\mathbf{1}^{9,10}, \mathrm{Pd}$ and $\mathrm{Pt}$ for $\mathbf{2}^{11}$ and $\mathrm{Hg}$ for $\mathbf{3}^{7,12}$. Other related ligands have been also used for the formation of coordination networks. ${ }^{13}$ To the best of our knowledge, no copper 85 coordination network has been reported for tectons 1-3.

Since all tectons 1-3 are neutral units, in order to avoid the presence of unbound anions and furthermore to control the linear disposition of available coordination sites on the metal centre, copper acetate was chosen as a linear metallatecton. In 90 general, in presence of ligands offering donor atoms such as nitrogen and oxygen, $\mathrm{Cu}(\mathrm{OAc})_{2}$ forms a binuclear neutral complex with square pyramidal geometry resulting from the bridging of the two $\mathrm{Cu}(\mathrm{II})$ centres by four acetate anions occupying the square base of the polyhedron (figure 1a). This

${ }_{95}$ dimer acts as a linear connector through the two free apical positions.

This dimeric unit has been extensively used for the formation of several coordination networks. ${ }^{14}$ A correlation between (i) the nature of the carboxylate ligand, (ii) the nature of the axial 100 ligands, (iii) the distorsion around the copper(II) ions and the amplitude of the antiferromagnetic coupling between both copper(II) ions has been investigated. ${ }^{15}$ For binuclear copper units containing carboxylate ligands as bridging ligands and ligands bearing $\mathrm{N}$ donor atoms, other coordination modes of 105 carboxylate are observed, ${ }^{16}$ however, for the majority of cases reported, the geometry around copper(II) atoms is square pyramidal.

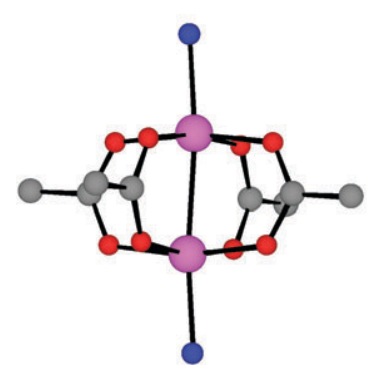

a)

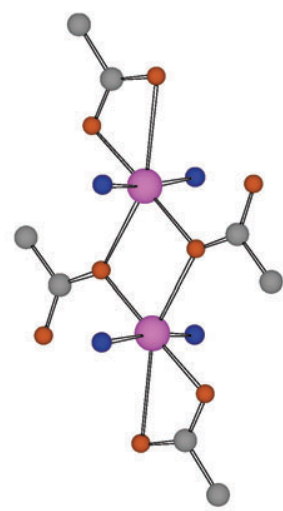

b)

Figure 1: Two different binuclear copper complexes (a) square 115 pyramidal environment of Copper(II) (b) deformed octahedral environment of copper(II).

At room temperature, the mixing of all three ligands 1-3 (in DMSO) with copper(II) acetate (in $\mathrm{MeOH}$ or $\mathrm{EtOH}$ ) in $1 / 1$ 120 ratio afforded crystalline material that was structurally investigated by X-ray diffraction methods on single-crystals (see Table 1 for details).

\section{Structural Analysis}

1-( $\left.\mathbf{C u}(\mathbf{O A c})_{2}\right)_{2}$ : The crystal (triclinic, P-1) is composed of one 125 molecule of the tecton $\mathbf{1}$, one $\left(\mathrm{Cu}(\mathrm{OAc})_{2}\right)_{2}$ dimer and two DMSO solvent molecules. No specific interactions between the DMSO molecules and the other two components are detected.

Tectons $\mathbf{1}$ are interconnected by $\left(\mathrm{Cu}(\mathrm{OAc})_{2}\right)_{2}$ dimers, leading 130 thus to a 1-D zigzag type coordination network (Figure 2). Due to the V-shape of the tecton $\mathbf{1}$, the geometrical feature of the zigzag chain is rather pronounced (torsion angle of $c a$. $\left.60^{\circ}\right)$. For the organic tecton 1, both amide junctions $\left(\mathrm{d}_{\mathrm{C}=\mathrm{O}}=\right.$ $1.228 \AA, \mathrm{dN}_{\mathrm{N}} \mathrm{C}(\mathrm{O})=1.341 \AA$ ) are in trans configuration. The 135 two amide groups adopt the antiparallel arrangement. The oxygen and nitrogen atoms of the amide junctions are not coordinated to the copper ions but form two intermolecular $\mathrm{H}-$ bonds between the $\mathrm{NH}$ and $\mathrm{CO}$ moieties $(\mathrm{N}-\mathrm{O}$ distances of $2.94 \AA$ and $3.08 \AA$ ).

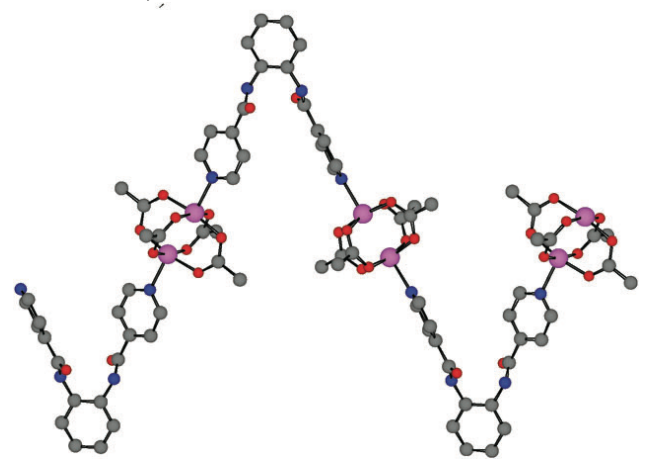

Figure 2: A portion of the structure of the 1-D coordination network $\left[1-\left(\mathrm{Cu}(\mathrm{OAc})_{2}\right)_{2}\right]$ formed between the tecton $\mathbf{1}$ and $\mathrm{Cu}(\mathrm{OAc})_{2}$.complex. $\mathrm{H}$ atoms and DMSO solvent molecules are not represented for clarity. 145 For bond distances and angles see text. 
The geometry around the copper atoms is square pyramidal (Figure 1a), with the square base occupied by four oxygen atoms belonging to four acetate groups $(\mathrm{Cu}-\mathrm{O}$ distance of ca $1501.97 \AA, \mathrm{OCuO}_{\text {cis }}$ angle in the range of $88.6^{\circ}$ and $90.7^{\circ}$ and $\mathrm{OCuO}$ trans angle in the range of $168.5^{\circ}$ and $169.0^{\circ}$ ) and the axial position by a nitrogen atom belonging to the tecton 1 $(\mathrm{Cu}-\mathrm{N}$ distance of $c a 2.15 \AA$ and $2.18 \AA, \mathrm{NCuO}$ angle in the range of $91.7^{\circ}$ and $99.5^{\circ}$ ). The $\mathrm{Cu}-\mathrm{Cu}$ distance in the dimeric

155 core is $2.61 \AA$. The shortest $\mathrm{Cu}-\mathrm{Cu}$ distance between two dimers is $8.81 \AA$.

In the lattice, in the $\mathrm{b}$ direction, the chains are arranged in parallel fashion with van der Waals interactions between the 160 methyl groups of the acetate moieties (C-C distance of $c a$ $4.05 \AA$ ) and in the other direction two adjacent chains are disposed in alternate fashion, leading thus to the formation of forming lozenge-type channels which are filled with DMSO solvent molecules (Figure 3 ).

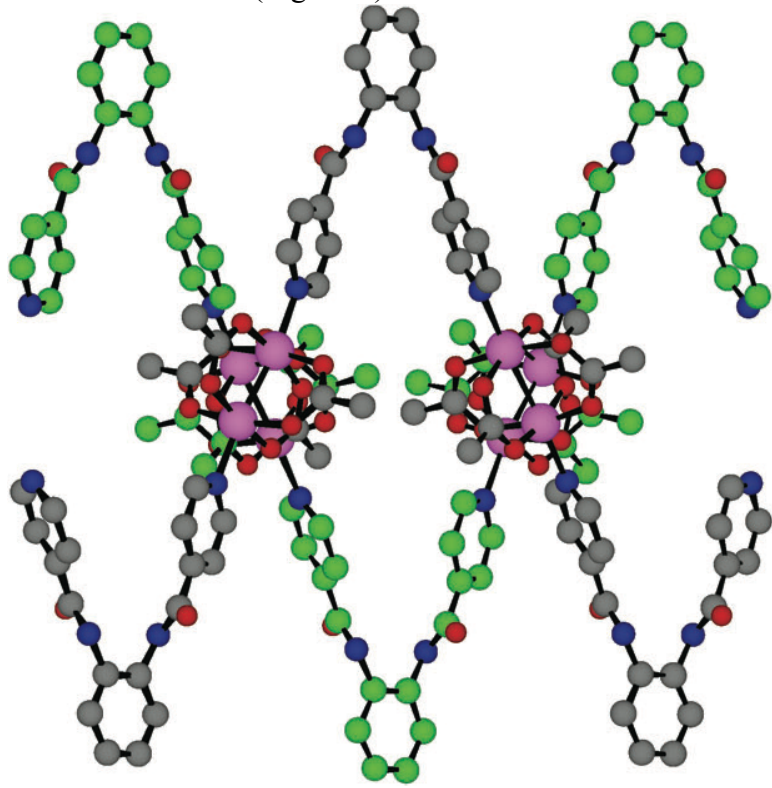

Figure 3: A portion of structures of $\left[1-\left(\mathrm{Cu}(\mathrm{OAc})_{2}\right)_{2}\right]$ showing the packing of two 1-D networks generating lozenge-type channels. The two networks are differentiated by the colour of the carbon atoms (grey and green). $\mathrm{H}$ atoms and DMSO molecules are not represented 170 for clarity.

2-( $\left(\mathrm{Cu}(\mathrm{OAc})_{2}\right)_{2}$ : The crystal (monoclinic, $\mathrm{C} 2 / \mathrm{c}$ ) is composed of one molecule of the tecton 2 , one $\left(\mathrm{Cu}(\mathrm{OAc})_{2}\right)_{2}$ dimer and two $\mathrm{MeOH}$ solvent molecules. No specific interactions between 175 the $\mathrm{MeOH}$ molecules and the other components are detected.

Tectons 2 are again interconnected by $\left(\mathrm{Cu}(\mathrm{OAc})_{2}\right)_{2}$ dimers behaving again as linear connectors, generating again a 1-D zigzag type coordination network (Figure 4). Due to the less pronounced $\mathrm{V}$-shape of the tecton 2 , the zigzag chain is 180 smoother (torsion angle of $c a .140^{\circ}$ ) than in the case of 1 (angle of $60^{\circ}$ ). For the organic tecton 2 , both amide junctions $\left(\mathrm{d}_{\mathrm{C}=\mathrm{O}}=1.294 \AA, \mathrm{d}_{\mathrm{N}-\mathrm{C}(\mathrm{O})}=1.331 \AA\right)$ are again in trans configuration. Once again, the two amide groups adopt the antiparallel conformation.
${ }_{185}$ For the copper dimer, the same square pyramidal geometry with almost the same distances and angles $(\mathrm{Cu}-\mathrm{O}$ distance of ca $1.96 \AA$, $\mathrm{OCuO}_{\text {cis }}$ angle in the range of $88.7^{\circ}$ and $88.9^{\circ}$ and $\mathrm{OCuO}_{\text {trans }}$ angle in the range of $168.3^{\circ}$ and $168.4^{\circ}, \mathrm{Cu}-\mathrm{N}$ distance of $c a 2.18 \AA, \mathrm{NCuO}$ angle in the range of $94.5^{\circ}$ and $\left.19097.0^{\circ}\right)$ as in the case of $\mathbf{1}$ mentioned above, is observed (Figure 1a). The $\mathrm{Cu}-\mathrm{Cu}$ distance in the dimeric core is $2.61 \AA$. The shortest $\mathrm{Cu}-\mathrm{Cu}$ distance of $17.80 \AA$ between two dimers is considerably longer than the one observed in the case of $\mathbf{1}$ $(8.81 \AA)$.

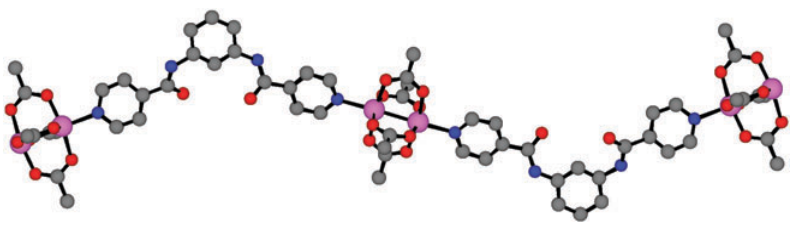

Figure 4: A portion of the structure of the 1-D coordination network [2- $\left.\left(\mathrm{Cu}(\mathrm{OAc})_{2}\right)_{2}\right]$ formed between the tecton 2 and $\mathrm{Cu}(\mathrm{OAc})_{2}$.complex. $\mathrm{H}$ atoms and $\mathrm{MeOH}$ solvent molecules are not represented for clarity. For bond distances and angles see text. 200

The 1-D networks are packed in a parallel fashion within planes perpendicular to the $c$ axis. The consecutive planes are tilted by $\mathrm{ca} 30^{\circ}$. The packing of planes along the $\mathrm{c}$ axis leads to the formation of rectangular channels ( $7.8 \AA \times 14 \AA$ ), which 205 are occupied by $\mathrm{MeOH}$ molecules. The shortest distance between copper dimers localised in two adjacent planes is $6.98 \AA$ (Figure 5).

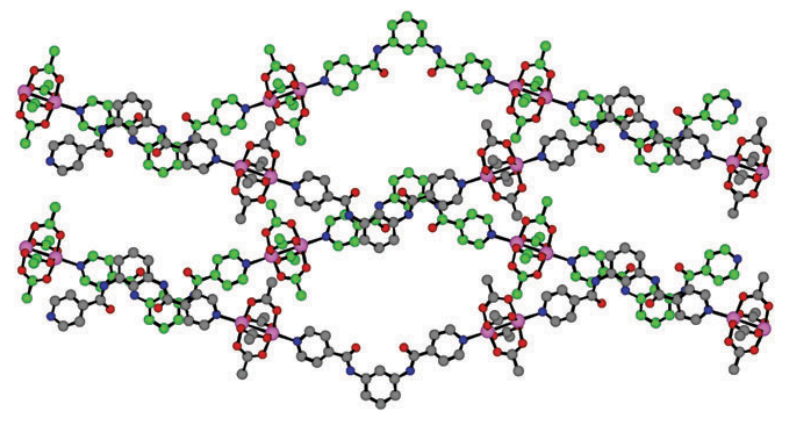

210 Figure 5: A portion of structures of $\left[2-\left(\mathrm{Cu}(\mathrm{OAc})_{2}\right)_{2}\right]$ showing the packing of 1-D networks generating lozenge-type channels. The 1-D networks are differentiated by the colour of the carbon atoms. Networks with the same colour (grey or green) are in the same plane. $\mathrm{H}$ atoms and $\mathrm{MeOH}$ molecules are not represented for clarity. 215

3-( $\left(\mathbf{C u}(\mathrm{OAc})_{2}\right)_{2}$ : The crystal (monoclinic, $\left.\mathrm{P} 2(1) / \mathrm{n}\right)$ is composed of one molecule of the tecton $\mathbf{3}$ and one $\left(\mathrm{Cu}(\mathrm{OAc})_{2}\right)_{2}$ dimer, however of different type. No solvent molecule is present in the crystal.

220 The overall structure is a 2-D coordination network with a different role played by the copper dimer (Figure 6). For the organic tecton $\mathbf{1}$, both amide junctions $\left(\mathrm{d}_{\mathrm{C}=\mathrm{O}}=1.212 \AA\right.$, $\mathrm{d}_{\mathrm{N}}$ $\mathrm{C}(\mathrm{O})=1.355 \AA)$ are again in trans configuration. The two amide groups again adopt the antiparallel arrangement. The 225 oxygen and nitrogen atoms of the amide junctions do not participate in the coordination of the metal centre. 
Interestingly, in marked contrast with the two cases mentioned above, the copper bimetallic unit does not behave as the often observed linear connector. ${ }^{14}$ In fact, the coordination 230 geometry around $\mathrm{Cu}(\mathrm{II})$, instead of being square pyramidal, is a distorted octahedral as shown in Figure $1 \mathrm{~b}$. The copper centre is hexacoordinated and its coordination sphere is composed of four oxygen atoms occupying the square base of the octahedron and two nitrogen atoms of the pyridine type 235 belonging to two consecutive tectons $3(\mathrm{~N}-\mathrm{Cu}$ distances of 2.019 and $2.028 \AA$ ). The two nitrogen atoms occupy the apical positions ( $\mathrm{NCuN}$ angle of $\left.170^{\circ}\right)$. Among the four acetate units forming the dimer, two are terminal with one short (2.000 $\AA$ ) and one long (2.624 $\AA$ ) $\mathrm{Cu}-\mathrm{O}$ distances and a $\mathrm{OCuO}$ angle of $24055.0^{\circ}$. The other two acetate anions are bridging the two metal centres again with one short $(2.030 \AA)$ and one long $(2.333 \AA)$ $\mathrm{Cu}-\mathrm{O}$ distances and with a $\mathrm{CuOCu}$ angle of $103.7^{\circ}$. To the best of our knowledge, this coordination mode of acetate and $\mathrm{N}$ donor atoms has never been observed before. Consequently, 245 the $\mathrm{Cu}-\mathrm{Cu}$ distance of $3.436 \AA$ is considerably longer than 2.613 observed in the case of $\mathbf{1}$ and 2 . Due to this peculiar mode of coordination, the 2-D network may be described as 1D copper networks obtained upon bridging of tectons 3 by copper ions and their interconnection by the bridging of

${ }_{250} \mathrm{Cu}(\mathrm{II})$ ions by acetate anions (Figure 6). The arrangement of the 2-D networks leads to a compact structure with no cavity available for the inclusion of solvent molecules.

255

260

265

275

Figure 6: A portion of the structure of the 1-D coordination network [3- $\left.\left(\mathrm{Cu}(\mathrm{OAc})_{2}\right)_{2}\right]$ formed between the tecton 3 and $\mathrm{Cu}(\mathrm{OAc})_{2}$.complex. $\mathrm{H}$ atoms are not represented for clarity. For bond distances and angles see text.

280

\section{Conclusions}

For both bismonodentate tectons $\mathbf{1}$ and $\mathbf{2}$ possessing a Vshape, copper diacetate behaves as a linear connector leading thus to two analogous 1-D coordination networks of the 285 zigzag type. Based on geometrical features of tectons $\mathbf{1}$ and $\mathbf{2}$, as expected, the zigzag chain observed with tecton 2 possesses a smoother angle than the one observed with tecton $\mathbf{1}$. This observation confirms the existence of a correlation between geometrical characteristics of the organic tecton such as the 290 bent angle between the two coordinating sites (Scheme $2 \mathrm{~b}$ and c) and the bent angle of the zigzag type 1-D networks generated upon interconnection of tectons $\mathbf{1}$ and $\mathbf{2}$ by a linear connector such as copper diacetate (Figure 2a). However, interestingly but unexpectedly, in the case of the tecton 3 295 which should have behaved as a linear construction unit (Figure 1a), instead of a 1-D network, a 2-D network is obtained. Although the tecton 3 behaves as an almost linear unit, probably due to packing effects, the nature of the connecting metallic part is different. Indeed, in that case, the 300 copper centre still forms a binuclear complex however it changes its coordination geometry from square pyramidal to octahedral. This mode of connectivity is rather unusual for binuclear copper(II) carboxylate complexes. This change in the coordination mode leads to the formation of a 2-D 305 network. Magnetic properties of cystalline materials obtained with tectons 1-3 will be investigated. Furthermore, the use of tectons 1-3 for the formation of coordination networks with other metal cations such as cobalt and iron is currently under investigation.

\section{${ }_{310}$ Exprimental section}

The synthesis of ligands $\mathbf{1}^{9}, \mathbf{2}^{11 \mathrm{a}}$ and $\mathbf{3}^{7,12}$ has been previously reported.

The generation of $\mathbf{1}-\left(\mathrm{Cu}(\mathrm{OAc})_{2}\right)_{2}$ coordination network was achieved in a crystallisation tube $($ Height $=15 \mathrm{~cm}$, diameter $=$ $3150,4 \mathrm{~cm})$ by slow diffusion at room temperature of a $\mathrm{EtOH}$ solution $(1 \mathrm{ml})$ containing $\mathrm{Cu}(\mathrm{OAc})_{2} \cdot \mathrm{H}_{2} \mathrm{O}\left(6.10^{-6}\right.$ moles $)$ into a DMSO solution $(1 \mathrm{ml})$ of the ligand $1\left(6.10^{-6}\right.$ moles $)$. After one week, blue crystals were obtained which were filtered and dried under vacuum. Molecular formula: (1$\left.320\left(\mathrm{Cu}(\mathrm{OAc})_{2}\right)_{2}\right) \bullet\left(\mathrm{CH}_{3} \mathrm{SOCH}_{3}\right)_{2} \quad\left(837.8 \mathrm{gmol}^{-1}\right)$. Elemental analysis: calcd: $\mathrm{C}: 43.0 \%, \mathrm{H}: 4.6 \%, \mathrm{~N}: 6.7 \%$; found: $\mathrm{C}: 42.6 \%$, H: $4.2 \%$, N: $6.6 \%$.

The generation of $\mathbf{2}-\left(\mathrm{Cu}(\mathrm{OAc})_{2}\right)_{2}$ coordination network was achieved in a crystallisation tube $($ Height $=15 \mathrm{~cm}$, diameter $=$ $3250,4 \mathrm{~cm})$. Upon slow diffusion at room temperature of a $\mathrm{MeOH}$ solution $(1 \mathrm{ml})$ containing $\mathrm{Cu}(\mathrm{OAc})_{2} \cdot \mathrm{H}_{2} \mathrm{O}\left(6.10^{-6}\right.$ moles $)$ into a DMSO solution $(1 \mathrm{ml})$ of the ligand $2\left(6.10^{-6}\right.$ moles $)$ blue crystals were obtained after $c a$ one week. They were filtered and dried under vacuum. Molecular formula: (2$\left.\left.{ }_{330}\left(\mathrm{Cu}(\mathrm{OAc})_{2}\right)_{2}\right) \bullet\left(\mathrm{CH}_{3} \mathrm{OH}\right)_{2}\right) \quad\left(725.7\right.$ gmol $\left.^{-1}\right)$. Elemental analysis: calcd : C: $45.1 \%, \mathrm{H}: 4.6 \%$, N: 7.5\%; found: C: $45.0 \%, \mathrm{H}: 4.1 \%$, $\mathrm{N}: 7.4 \%$.

The generation of $\mathbf{3}-\left(\mathrm{Cu}(\mathrm{OAc})_{2}\right)_{2}$ coordination network was also achieved in a crystallisation tube (Height $=15 \mathrm{~cm}$, 335 diameter $=0,4 \mathrm{~cm})$. Upon slow diffusion at room temperature of a EtOH solution $(1 \mathrm{ml})$ containing $\mathrm{Cu}(\mathrm{OAc})_{2} \cdot \mathrm{H}_{2} \mathrm{O}\left(6.10^{-6}\right.$ moles) into a DMSO solution $(1 \mathrm{ml})$ of the ligand $3\left(6.10^{-6}\right.$ moles). However, in marked contrast with the two above mentioned cases, few blue crystals were obtained after several 
340 weeks. Owing to the small quantities of collected crystals, no elemental analysis has been performed.

Crystallography:

Data were collected at 173(2) K on a Bruker SMART CCD 345 Diffractometer equipped with an Oxford Cryosystem liquid $\mathrm{N}_{2}$ device, using graphite-monochromated Mo-K $\alpha \quad(\lambda=$ 0.71073 ) radiation. For all structures, diffraction data were corrected for absorption and structural determination was achieved using the APEX (1.022) package. All hydrogen 350 atoms have been calculated except those connected to disordered atoms. CCDC ????-???? contains the supplementary crystallographic data for this paper. These data can be obtained free of charge at www.ccdc.cam.ac.uk/conts/retrieving.html or from the ${ }_{355}$ Cambridge Crystallographic data Centre, 12 Union Road, Cambridge CB2 1EZ, UK; Fax: (Internat.) +44-1223/336-033; E-mail: deposit@ccdc.cam.ac.uk.

Acknowledgements Université Louis Pasteur, Institut 360 Universitaire de France, the CNRS and the Ministry of Education and Research are acknowledged for financial support and for a scholarship to J. P.

\section{Notes and references}


${ }_{365}$ Table 1: Data collection and refinements for 1-(Cu(OAc $\left.)_{2}\right)_{2}, \mathbf{2}-\left(\mathrm{Cu}(\mathrm{OAc})_{2}\right)_{2}$ and 3-(Cu(OAc) $)_{2}$.

\begin{tabular}{|c|c|c|c|}
\hline & $1-\left(\mathrm{Cu}(\mathrm{OAc})_{2}\right)_{2}$ & $2-\left(\mathrm{Cu}(\mathrm{OAc})_{2}\right)_{2}$ & 3- $\left(\mathrm{Cu}(\mathrm{OAc})_{2}\right)_{2}$ \\
\hline Empirical Formula & $\mathrm{C}_{18} \mathrm{H}_{14} \mathrm{~N}_{4} \mathrm{O}_{2} \bullet\left(\mathrm{Cu}\left(\mathrm{CH}_{3} \mathrm{C}\right.\right.$ & $\mathrm{C}_{18} \mathrm{H}_{14} \mathrm{~N}_{4} \mathrm{O}_{2} \bullet\left(\mathrm{Cu}\left(\mathrm{CH}_{3}\right.\right.$ & $\mathrm{C}_{18} \mathrm{H}_{14} \mathrm{~N}_{4} \mathrm{O}_{2} \cdot\left(\mathrm{Cu}\left(\mathrm{CH}_{3}\right.\right.$ \\
\hline & $\left.\mathrm{OO})_{2}\right)_{2} \bullet\left(\mathrm{CH}_{3} \mathrm{SOCH}_{3}\right)_{2}$ & $\left.\mathrm{COO})_{2}\right)_{2} \bullet\left(\mathrm{CH}_{3} \mathrm{OH}\right)_{2}$ & $\left.\mathrm{COO})_{2}\right)_{2}$ \\
\hline Molecular weight $\left[\mathrm{gmol}^{-1}\right]$ & 835.85 & 745.68 & 499.96 \\
\hline Crystal system & Triclinic & Monoclinic & Monoclinic \\
\hline Space group & P-1 & $\mathrm{C} 2 / \mathrm{c}$ & $\mathrm{P} 2(1) / \mathrm{n}$ \\
\hline $\mathrm{a}[\AA \AA]$ & $8.2271(2)$ & $33.799(1)$ & $13.6671(13)$ \\
\hline $\mathrm{b}[\AA]$ & $14.3223(3)$ & $12.7452(5)$ & $11.5908(8)$ \\
\hline $\mathrm{c}[\AA]$ & $15.7025(4)$ & $8.5671(5)$ & $14.1521(16)$ \\
\hline$\alpha\left[^{\circ}\right]$ & $76.877(4)$ & 90 & 90 \\
\hline$\beta\left[^{\circ}\right]$ & $89.004(4)$ & $95.297(5)$ & $117.785(3)$ \\
\hline$\gamma\left[{ }^{\circ}\right]$ & $82.816(4)$ & 90 & 90 \\
\hline $\mathrm{V}\left[\AA^{3}\right]$ & 1787.66(7) & $3674.7(3)$ & 1983.4(3) \\
\hline Z & 2 & 4 & 4 \\
\hline color & blue & blue & blue \\
\hline Crystal size $[\mathrm{mm}]$ & $0.16 \times 0.06 \times 0.04$ & $0.08 \times 0.06 \times 0.06$ & $0.15 \times 0.15 \times 0.15$ \\
\hline$\rho_{\text {calcd }}\left[\mathrm{g} \mathrm{cm}^{-3}\right]$ & 1.55 & 1.35 & 1.674 \\
\hline$\mu\left[\mathrm{mm}^{-1}\right]$ & 1.372 & 1.216 & 1.153 \\
\hline$\lambda[\AA]$ & 0.71073 & 0.71073 & 0.71073 \\
\hline Number of reflections collected & 14823 & 9707 & 18010 \\
\hline Number of data with $\mathrm{I}>2 \sigma(\mathrm{I})$ & 6842 & 2314 & 4373 \\
\hline $\mathrm{R}$ & 0.076 & 0.105 & 0.0349 \\
\hline Rw & 0.095 & 0.134 & 0.0872 \\
\hline GOF & 1.149 & 1.252 & 1.025 \\
\hline
\end{tabular}

\section{${ }_{370}$ Graphical abstract:}

The combination of three isomeric tectons based on 1,2-, 1-3 and 1-4-phenylenediamine backbones bearing two isonicotinoyl units with $\mathrm{Cu}(\mathrm{OAc})_{2}$ leads to the formation of 1-D and 2-D coordination networks rtesulting from the interconnection of the organic tectons with two diffrent types of copper dimers. 
${ }^{1}$ M. W. Hosseini, Cryts. Eng. Comm., 2004, 6, 318.

2 a) S. R. Batten, R. Robson, Angew. Chem. Int. Ed., 1998, 37, 1460; R. Robson, Comprehensive Supramolecular Chemistry, J-L. Atwood, J.E.D. Davies, D.D. Macnicol, F. Vögtle Eds., vol 6, 1996, p 733; b) M. W. Hosseini, in NATO ASI Series, Eds. D. Braga, F. Grepiono, G. Orpen, Serie C, Kluwer, Dordrecht, Netherlands, 1999, 538, 181; c) A. J. Blake, N. R. Champness, P. Hubberstey, W.-S. Li, M. A. Withersby, M. Schröder, Coord. Chem. Rev.,1999, 193, 117; d) G. F. Swiergers, T. J. Malefetse, Chem. Rev., 2000, 100, 3483; e) B. Moulton, M.J. Zaworotko, Chem. Rev., 2001, 101, 1629; f) M. Eddaoui, D.B. Moler, H. Li, B. Chen, T.M. Reineke, M. O’Keefe, O. M. Yaghi, Acc. Chem. Res., 2001, 34, 319; g) L. Carlucci, G. Ciani, D. M. Proserpio, Coord. Chem. Rev., 2003, 246, 247; h) C. Janiak, Dalton Trans. 2003, 2781; i) S. Kitagawa, Angew. Chem. Int Ed., 2004, 43, 2434; j) G. Ferey, C. Mellot-Draznieks, C. Serre, F. Millange, Acc. Chem. Res., 2005, 38, 218; k) D. Bradshaw, J. B. Claridge, E. J. Cussen, T. J. Prior, M. J. Rosseinsky, Acc. Chem. Res., 2005, 38, 273.

${ }^{3}$ M. Simard, D. Su, J. D. Wuest, J. Am. Chem. Soc., 1991, 113, 4696.

${ }^{4}$ M. W. Hosseini, Acc. Chem. Res., 2005, 38, 313.

${ }^{5}$ M. W. Hosseini, Chem. Comm., 2005, 582.

${ }^{6}$ a) M. Henry, M. W. Hosseini, New. J. Chem., 2004, 897; b) E. Deiters, V. Bulach, M. W. Hosseini, Chem. Comm., 2005, 3906 ; c) E. Deiters, V. Bulach, N. Kyritsakas, M. W. Hosseini, New J. Chem., 2005, 29, 1508 ; d) D. Pocic, J.-M. Planeix, N. Kyritsakas, A. Jouaiti, M. W. Hosseini, Cryst. Eng. Comm., 2005, 7, 624.

${ }^{7}$ J. Pansanel, A. Jouaiti, S. Ferlay, M. W. Hosseini, J.-M. Planeix, N. Kyritsakas, New J. Chem., 2006, $1,71$.

${ }^{8}$ T. J. Burchell, D. J. Eisler, M. C. Jennings and R. J. Puddephatt, Chem. Commun., 2003, 2228.

${ }^{9}$ T. J. Burchell, D. J. Eisler, R. J. Puddephatt Inorg. Chem. 2004, 43, 5550.

${ }^{10}$ a) T. J. Burchell, D. J. Eisler, M. C. Jennings, R. J. Puddephatt Chem. Commun., 2003, 2228. b) T. J. Burchell, D. J. Eisler, R. J. Puddephatt, Chem. Commun., 2004, 944.

11 a) Z. Quin, M. C. Jennings, R. J. Puddephatt, Inorg. Chem., 2003, 42, 1956.; b) N. L. S. Yue, D. J. Eisler, M. C. Jennings, R. J. Puddephatt, Inorg. Chem., 2004, 43, 7671

${ }^{12}$ Y.-Y. Niu, Y.-L. Song, J. Wu, H. Hou, Y. Zhu and X. Wang, Inorg. Chem. Commun., 2004, 471.

${ }^{13}$ a) S. Muthu, J. H. K. Yip, J. J. Vittal, J. Chem. Soc., Dalton Trans., 2001, 3577; b) Z. Quin, M. C. Jennings, R. J. Puddephatt, Chem. Eur. J., 2002, 8, 735 ; c) S. Muthu, J. H. K. Yip, J. J. Vittal, J. Chem. Soc., Dalton Trans., 2002, 4561; d) Z. Quin, M. C. Jennings, R. J. Puddephatt, Inorg. Chem., 2003, 42, 1956; e) T. J. Burchell, D. J. Eisler, R. J. Puddephatt, Chem. Commun., 2004, 944; f) N. L. S. Yue, M. C. Jennings, R. J. Puddephatt, Inorg. Chem., 2005, 44, 1125; g) N. L. S. Yue, M. C. Jennings, R. J. Puddephatt Chem. Commun., $2005,4792$.

14 a)V. M. Rao, D. N. Sathyanarayana, H. Manohar, J. Chem. Soc., Dalton Trans., 1983, 2167 ; b) S. C. Davies, M. C. Durrant, D. L. Hughes, K. Leidenberger, C. Stapper, R. L. Richards J. Chem. Soc., Dalton Trans., 1997, 2409; c) S. R. Batten, B. F. Hoskins, B. Moubaraki, K. S. Murray, R. Robson Chem. Commun., 2000, 1095; d) B. Moulton, J. Lu, M. J. Zaworotko, J. Am. Chem. Soc., 2001, 123, 9224; e) G. S. Papaefstathiou, L. R. MacGillivray Angew. Chem. Int. Ed., 2002, 41, 2070; f) W. J. Belcher, C. A. Longstaff, M. R. Neckenig, J. W. Steed Chem. Commun., 2002,1602; g) B. Zimmer, V. Bulach, M. W. Hosseini, A. De Cian, N. Kyritsakas, Eur. J. Inorg. Chem, 2002, 3079; h) C. B. Aakeröy, A. M. Beatty, J. Desper, M. O Shea, J. Valdes-Martinez Dalton Trans., 2003, 3956; i) N. Schultheiss, C. L. Barnes, E. Bosch Cryst. Gr.\&Des., 2003, 3, 573; j) Z. Huang, H.-B. Song, M. Du, S.-T. Chen, X.-H. Bu, J. Ribas Inorg. Chem., 2004, 43, 931; j) E. Graf, M. W. Hosseini, J.-M. Planeix, N. Kyritsakas, New J. Chem, 2005, 29, 343.

${ }^{15}$ A. Rodriguez-Fortea, P. Alemany, S. Alvarez, E. Ruiz, Chem. Eur. J., 2001, 7, 627.

16 a) G. Christou, J. S. P. Perlepes, E. Libby, K. Folting, J. C. Huffman, R. J. Webb, D. N. Hendrickson Inorg. Chem,. 1990, 29 , 3657 ; b) S.P. Perlepes, J.C. Huffman, G. Christou, Polyhedron, 1991, 10, 2301 ; c) S.P. Perlepes, J.C. Huffman, G. Christou, Polyhedron, 1992, 12, 1471; d) S.P. Perlepes, E. Libby, W.E. Streib, K. Folting, G. Christou, Polyhedron, 1992, 11, 923; e) S.P. Perlepes, J.C. Huffman, G. Christou, S. Paschalidou, Polyhedron, 1995 ; 14, 1073 ; f) A. Castineiras, S. Balboa, E. Bermejo, R. Carballo, B. Covelo, J. Borras, J. A. Real Z. Anorg. Allg. Chem., 2002, 628, 1116 ; g) D. Braga, M. Polito, M. Bracaccini, D. D’Addario, E. Tagliavini, D. M. Proserpio, F. Grepioni Chem. Commun., 2002, 1080 ; 